\title{
A Terra à vista
}

Por Adriano Belisário

O desejo de produzir imagens é indissociável do processo de expansão das tecnologias espaciais. De quê adianta sair da Terra se não é possível ver nada novo? Junto à vontade humana de transcender a Terra, há também a recorrente necessidade de traduzir isto em imagens. Imagens estas que parecem nos afetar de um modo muito particular, exercendo um impacto especial sobre nós. Afinal, são capazes de - literalmente - mudar nossa visão de mundo.

Isto as convertem em signos poderosos. A criação e circulação destas imagens sempre foram importantes instrumentos de poder. Basta lembrar do uso feito sobre imagens espaciais em casos clássicos, como o vídeo dos astronautas caminhando sobre a lua durante a Guerra Fria, ou contemporâneos, como o bilionário Elon Musk lançando ao espaço o carro de sua marca, a fim de promovê-la na Terra com uma transmissão ao vivo na Internet, neste ano de 2018.

De fato, a consciência sobre o poder destas imagens parece tão antiga quanto as próprias. Steward Brand foi um dos primeiros a intuir isto. Um dos ícones da contracultura tecnológica norte-americana de meados do século passado, Brand lançou uma campanha viral em 1966 por meio de posters e buttons: "Por que ainda não vimos uma foto da Terra inteira?". Influenciado por Buckminster Fuller e inspirado pelo ambiente lisérgico da época, Brand perseguia esta imagem pois vislumbrava que a foto de "toda a Terra" ("whole Earth") ajudaria a humanidade a se enxergar como parte de um todo, trazendo assim uma visão mais holística para nossa compreensão de mundo. Por acaso ou não, no ano seguinte, a NASA publicou a primeira foto colorida onde se via todo planeta. E Brand usou a imagem para estampar a capa de uma das publicações fundadoras da cibercultura norte-americana: The Whole Earth Catalog.

Sobre aquele período, Herscher (2014) nos lembra que não foi coincidência o fato das imagens satelitais e do ativismo de direitos humanos terem se desenvolvido praticamente no mesmo período, durante a Guerra Fria, pois ambos são como uma resposta às ameaças e conflitos do período. Em 196o, os Estados Unidos colocaram em órbita o Corona, seu primeiro satélite de vigilância. Um olho invisível que - sobrevoando a Terra do espaço - 
pairava sobre os inimigos. No ano seguinte, a Anistia Internacional foi fundada em Londres. No entanto, apesar do interesse da sociedade civil, durante muitas décadas, o conjunto destas imagens espaciais da Terra foram acessadas e utilizadas praticamente apenas para fins de inteligência de Estado ou em contextos militares. Vide o governo norte-americano, líder no assunto, que só admitiu a existência do projeto Corona em 1978 e só liberou suas imagens em 1995.

A situação mudou nos anos 1990 e início do século XXI. A partir de então, observamos também imagens de satélite sendo produzidas e vendidas para fins comerciais. Isto ampliou o acesso para além das agências estatais das grandes potências mundiais, incluindo também empresas, pesquisadores, organizações de direitos humanos e mesmo instituições governamentais de países sem programas espaciais desenvolvidos. Assim, de meados do século passado até hoje, as imagens produzidas por satélite passaram por transformações técnicas relacionadas à resolução das imagens, por exemplo, mas também nas próprias condições sociais de sua produção e fruição.

É verdade que os dados de sensoriamento espaciais em geral seguem sendo registradas pelo aparato estatal ou por grandes corporações, devido aos custos envolvidos. No geral, ainda soa algo distante e improvável para a maioria dos movimentos da sociedade civil a ideia de lançar seu próprio satélite ao espaço. Porém, se antes a produção das imagens de satélite estava restrita e à serviço do discurso oficial, agora, ainda que os satélites em si pertençam a governos ou empresas, centenas de ativistas, pesquisadores acadêmicos e artistas produzem imagens a partir de dados de satélites, afim de explorar um determinado assunto ou estética.

Não é acidental aqui ênfase no conceito de produção, em contraposição à ideia de representação da Terra ou do território. As etapas técnicas relacionadas ao registro das imagens satelitais deixam claro que não se trata aqui de uma representação da realidade objetiva, mas antes da produção de um registro da realidade. Produção esta que depende não só das características técnicas dos aparatos em questão, como também do tipo de discurso que se pretende veicular.

Os satélites são artefatos técnicos postos em órbita para registrar alterações eletromagnéticas à distância - ou, em termos técnicos, realizar sensoriamento remoto.

\footnotetext{
${ }^{1} \mathrm{~A}$ respeito de trabalhos artísticos com imagens de satélite, vide o projeto Daily Overview (http://www.dailyoverview.com/sixtynine)
} 
Estes aparelhos registram tais alterações em diferentes bandas do espectro eletromagnético. A depender dos objetivos em torno da produção da imagem algumas bandas são escolhidas em detrimentos de outras.

Assim, é possível criar uma visualização com cores naturais para simular como seria uma representação próxima ao do olhar humano às radiações registradas naquele momento, enquanto bandas invisíveis, mais próximas do infra-vermelho, são utilizadas em técnicas como o $\mathrm{NDVI}^{2}$ para representar alterações na vegetação. A produção das imagens satelitais é indissociável desta composição de bandas.

Logo, desde sua própria elaboração, estas imagens estão longe de serem neutras, como um reflexo puramento objetivo da realidade, desconectado de implicações políticas. Aqui, tal como na fotografia, o enquadramento em si já é também um ato discursivo, uma escolha política do que será visto e como será visto, a depender das bandas utilizado. No caso das imagens de satélite, isso passa pela definição não só de um território, mas também de um período do tempo e da já mencionada composição de bandas.

Além de vigilância estatal, atualmente estas imagens são intensamente usadas em diferentes campos, que vão do agronegócio ao planejamento urbano, mas passam também pelo monitoramento ambiental, destacando-se aí a larga experiência brasileira no uso destas tecnologias para combater desmatamento ilegal na Amazônia (BACKER et al, 2006), e pelo ativismo de direitos humanos ou pela arqueologia espacial, que busca nos registros de satélites rastos de civilizações passadas³.

Longe de esgotar as reflexões e referências em torno deste assunto, este breve ensaio reúne alguns breves comentários sobre as apropriações das imagens de satélite por diferentes iniciativas da sociedade civil, que vão da defesa do meio ambiente aos direitos humanos. Ainda que os poucos repositórios de imagens satelitais abertos ao público pertençam em geral a grandes empresas estadonidenses, como a Digitalglobe, as apropriações desta tecnologia e destas imagens passam não só pela resistência, como também pela denúncia das violações do Estado e corporações.

\footnotetext{
${ }^{2}$ Normalized difference vegetation index. Ref: https://en.wikipedia.org/wiki/Normalized difference vegetation index

${ }^{3}$ Sobre arqueologia espacial, é bastante conhecido o trabalho de Sarah Parcak no Egito, mas cientistas brasileiros e britânicos usaram técnicas semelhantes para investigar civilizações antigas da Amazônia. Ref: https://www.nature.com/articles/s41467-018-03510-7
} 
Aproximando-se da arte contemporânea e do ativismo de direitos humanos, o grupo multidisciplinar Forensic Architecture destaca-se internacionalmente por seus trabalhos de investigação e visualização de violações de direitos humanos em áreas de conflito mundo afora. Seu objetivo principal é empregar as práticas forenses para denunciar os crimes cometidos pelo Estado, apropriando-se desta técnica historicamente utilizada pelas forças oficiais contra a sociedade civil. Em um dos trabalhos, os pesquisadores do Forensic Architecture usaram imagens de satélites para investigar violência ambiental e ecocídio na Indonésia, após os incêndios florestais de 2015 que atingiram uma área de milhares de quilometros quadrados, formando uma nuvem tóxica colossal. Em outro, este tipo de registro serviu para apoiar a localização de bombardeios efetuados em Gaza. O material foi reunido em uma plataforma web reunindo diversas evidências de violações reunidas por organizações de direitos humanos na Palestina.

Outro grupo é o Bellingcat, que se destaca hoje como uma das principais agências independentes de serviços de inteligência de código-aberto (OSINT - Open Source Intelligence) atuando em temas de grande repercussão na geopolítica internacional. Em 2015, por exemplo, o grupo investigou o abatimento do vôo Malaysia Airlines 17 em uma zona controlada por separatistas pró-russos na Ucrânia, que matou quase 300 pessoas. Depois da tragédia, os governos russos e ucranianos passaram a se acusar mutuamente. Na época, o Ministério da Defesa russo foi a público para apresentar imagens de satélites da Ucrânia, que mostrariam uma movimentação suspeita de aviões oficiais, suspostamente no dia do abatimento do avião. No entanto, por meio de uma análise forense na imagem em si, nos seus metadados e em outras fotografias satelitais do mesmo terreno, Bellingcat concluiu que as imagens russas foram alteradas e eram de outra data, anterior à tragédia.

Para além do debate geopolítico ou factual sobre estes casos específicos, interessa aqui o uso das imagens de satélite enquanto evidência nesta guerra de versões. Esta evidência é algo produzido, não descoberto. No processo de desmontar a versão oficial russa, os pesquisadores do Bellingcat recorrem a uma técnica muito comum na análise e checagem dos registros apresentados: trata-se da busca por "assinaturas" nas imagens. Ou seja, signos que ajudem a localizar a imagem no tempo, como a expansão ou retração da vegetação ao longo de um período.

No Brasil, alguns pesquisadores e ativistas também já atentaram para o potencial destas imagens e recorreram a técnicas semelhantes. Membro do coletivo Forensic Architecture, Paulo Tavares em um projeto independente ('Memória da Terra') investiga o processo de remoção dos Xavantes de seu território durante a ditadura militar, fazendo uso de imagens 
de satélites, ao lado de uma extensa pesquisa sobre o tema. O documento é parte de um relatório pericial feito para o Ministério Público Federal ${ }^{4}$. A partir do acervo do satélite espião conhecido como Big Bird (KH-9 Hexagon), que operou em meados do século XX e cujas imagens vieram a público em 2002, o pesquisador localizou a região do povo Xavante de Marãiwatsédé, reconhecendo ali formas idênticas ao padrão de ocupação do território produzido pelas aldeias. Junto aos demais elementos probatórios, estas imagens se tornaram uma evidência chave para a ação judicial em questão que busca reparação em favor dos indígenas.

Atualmente, algumas plataformas online buscam aproximar as imagens satélites do público nãoespecializado. O SentinelHub ${ }^{5}$ permite aos usuários navegar pelo acervo de diferentes satélites, aplicando diferentes filtros e composições de banda às imagens, por exemplo. E há opções ainda mais intuitivas para leigos. Com interface inspirada no Instagram, o Snap Planet ${ }^{6}$ permite a qualquer pessoa explorar imagens de satélites de qualquer lugar do mundo em diferentes datas, tirando fotos para compartilhar na sua rede social ou fazendo sequências animadas para visualizar as mudanças sobre um território específico.

Antigamente o acesso aos dados satelitais, necessários para composição das imagens, não era tão facilitado como hoje em dia, de modo que a verificação do desmatamento demandava recursos consideráveis. Atualmente, o cenário é outro. Por exemplo, a plataforma web do Global Forest Watch ${ }^{7}$ permite explorar dados sobre e imagens satelitais de florestas, dando ao visitante a capacidade de usar as informações ali reunidas para identificar novas áreas de desmatamento. Hoje em dia, este processo não só é mais barato e acessível, como também há processos automatizados para identificar os padrões de desmatamento. Contudo, a facilidade ao acesso às imagens permite também que os próprios desmatadores tirem proveito delas. Uma reportagem de 2017 sobre crimes ambientais na Amazônia mostra que criminosos também acompanham as imagens

\footnotetext{
${ }^{4}$ Relatório pericial para o Inquérito Civil Público 1.20.004.000072/2014-82, movido pelo Ministério Público Federal Procuradoria da República do Município de Barra do Garças, para obtenção de reparação de danos materiais e morais sofridos pelo povo Xavante de Marãiwatsédé devido à remoção forçada de seu território originário em agosto de 1966.

${ }^{5}$ https://apps.sentinel-hub.com/eo-browser/

${ }^{6}$ https://snapplanet.io/

${ }^{7}$ https://www.globalforestwatch.org/
} 
satelitais e mudaram suas estratégias de derrubada de árvores, a fim de "burlar" o algoritmo que identifica padrões de desmatamento a partir das imagens de satélite ${ }^{8}$.

Além disto, atualmente, é possível encontrar gratuitamente na Internet imagens com resoluções medianas e comprar registros em alta resolução, onde cada pixel representa somente alguns centímetros. A tendência futura é de mais resolução nas imagens, permitindo observar do espaço objetos ainda menores, aumentando tanto a capacidade de vigilância dos Estados e empresas, mas também de uma maior disseminação de plataformas diversas, que buscam levar tais imagens à sociedade civil e um público nãoespecialista. Isto tende a acelerar ainda mais as mudanças - já em marcha - na forma como estas imagens são produzidas e

circulam em nossa sociedade, além de abrirem novos fronts de apropriação desta imagens para fins de ativismo da sociedade civil. Referências

HERSCHER, Andrew. Surveillant witnessing: satellite imagery and the visual politics of human rights.

Public Culture, 2014, 26.3 (74): 469-500.

Disponível em: https://sci-hub.tw/https://doi.org/10.1215/o8992363-2683639

BACKER, John; WILLIAMSON, Ray. Satellite imagery activism: Sharpening the focus on tropical deforestation. 2006. Disponível em:

https://onlinelibrary.wiley.com/doi/full/10.1111/j.14679493.2006.00236.x

\footnotetext{
${ }^{8}$ Ao invés de usar correntes e tratores para derrubar em massa as árvores, emprega-se mão de obra humana em situações análogas à escravidão para tombá-las com motosserra, dificultando assim a identificação por parte do Sistema de Deteç̧ão de Desmatamentos em Tempo Real (Deter) mantido pelo Instituto Nacional de Pesquisas Espaciais. A reportagem descreve como os desmatadores tentavam burlar o sistema: "Era um método lento que exigia muita mão de obra para cortar as árvores, uma a uma. Mas havia uma grande vantagem para os criminosos: comprava tempo para a quadrilha. A técnica não chamava a atenção do Deter, e os desmatadores podiam preparar o terreno aos poucos. As árvores com grandes copas ficavam para o final, dando a impressão de que a floresta estava intacta nas imagens de satélite. A semana toda, os chefes da quadrilha acessavam as imagens do Deter na internet e conferiam se o estrago chamava a atenção. Quando o terreno estava limpo na sombra das espécies mais altas, bastava serrar os últimos troncos e atear fogo para transformar o terreno em pasto rapidamente, sem dar chance para a fiscalização ambiental interromper a última etapa do processo". Fonte: https://medium.com/briostories/reidomato-7ff85450facf
} 